\title{
Mobile Device-Based Authentic Learning in Educational Environments: A Systematic Review
}

\author{
Abdul Latheef Mohamed \\ Kulliyyah of Education, \\ International Islamic University Malaysia, \\ Kuala Lumpur, Malaysia \\ abd.latheef.muhammad@gmail.com
}

\author{
Dawood A. Yahya Al-Hidabi \\ Kulliyyah of Education, \\ International Islamic University Malaysia, \\ Kuala Lumpur, Malaysia \\ dawood@iium.edu.my
}

\begin{abstract}
The rapid growth of mobile technology has opened new opportunities for learners to engage in authentic learning activities. The aim of this systematic review is to provide a synthesis of research on mobile device-based authentic learning in educational environments. This review has analyzed 72 studies published between 2010 and 2019 (until mid-November) in terms of major research purposes, methodologies, research outcomes, subject matter domains, educational levels, educational contexts and geographical distributions. Three research questions guided the review process. The findings showed the major research purpose of a majority of the studies was about investigating the effects of mobile device-based authentic learning on students. Researchers have mostly used mixed-methods research to examine the learning phenomena with a majority of the studies reporting positive learning outcomes. The analysis showed that science and literacy are the most represented content areas, while most of the studies were carried out at the elementary school level. More research was conducted in informal contexts than any other contexts, and the most predominantly used mobile device type was tablet computers. The findings revealed that there is a disproportionate distribution of studies in the literature in terms of geographical contributions as studies tend to concentrate on specific countries or regions.
\end{abstract}

Keywords: Authentic learning, mobile learning, situatedness, contextualization, mobile augmented, ubiquitous learning

\section{INTRODUCTION}

Effective learning occurs when learners are actively engaged in the learning process. In the traditional approach of learning, learners take a passive role of collecting facts and procedures from instructors by simply listening and observing. On the other hand, authentic learning approaches take a much more different form than the traditional methods of chalk-and-talk or direct instruction. In education, authentic learning has its foundations in the theory of situated cognition (Herrington, Reeves, \& Oliver, 2014), and supports the constructivist way of learning by enabling the learners to actively participate in real-world problems. Authentic learning refers to any process that involves dynamic interactions among the learner and other learners, the task they are given, and the learning environment (Herrington, 1997). In other words, authentic 
learning connects the learners to the real world, its challenges, knowledge applications and experiences.

The rapid growth of mobile technology has opened the doors for learners to engage in mobile device-based authentic learning activities, such as browsing the Web for answers to questions like, "What takes place in the process of photosynthesis?" and synthesizing the answers into a dynamic poster showing the process. The variety of distinguishable features of mobile devices support authentic learning spaces with the possibilities offered for instant access to information, context sensitivity, and real-time communication and feedback (Sung, Chang, \& Liu, 2016). According to Kearney, Schuck, Burden, and Aubusson (2012), mobile devices can enact both simulation and participation models of authentic learning through the device features that support situatedness and contextualization of learning environments. Learning activities that use the simulation model accommodate the learning space (e.g. the classroom) to provide real-world experiences providing the context that resembles actual settings; meanwhile, in case of learning tasks that fit into the category of the participation model, learners are situated in the actual environment, allowing them to directly interact with the real objects of their learning.

Recently, researchers have been systematically aggregating numerous empirical studies on mobile device-based learning approaches to achieve a better understanding of how mobile learning is supporting the learners. For example, Hedberg, Nouri, Hansen, and Rahmani (2018) reviewed the literature published from 2000 to 2017 on mobile supported augmented reality for learning, examining the learning and pedagogical aspects approached in those studies. Fu and Hwang (2018) reviewed research articles published between 2000 to 2017 on mobile technology-supported collaborative learning, aiming to investigate the recent research trends in specific areas such as the research methods, learning devices, learning environments, the participants, subjects, and measurement issues for mobile collaborative learning. Lin and Lin (2019) synthesized several studies published between 2005 to 2018 on mobile-assisted language learning (MALL) to examine how mobile technologies helped the ESL/EFL learners in vocabulary acquisition through L2 word retention.

On the other hand, there have been limited syntheses of research conducted on the area of mobile device-based authentic learning. An extensive literature search has yielded only one previous systematic review, conducted by Shadiev, Hwang, and Huang (2017), on mobile device-based authentic learning focusing on language learning. Their review has synthesized research articles published from 2007 to 2016 on mobile language learning in authentic environments, investigating the research trend, research focus, methodology, and current issues in the area. The review results showed that there has been an increase in the number of publications of research articles related to the area of mobile device-based language learning in authentic contexts.

To sum, those previous reviews have systematically analyzed numerous research articles on mobile device-based learning approaches. However, there is a lack of systematic knowledge available on mobile device-based authentic learning. Therefore, the aim of this systematic review is to provide the scholarly community with a current synthesis of research on mobile device-based authentic learning in educational environments in order to provide a 
comprehensive analysis of the collected studies. The research questions guiding this review are:

1. What were the major research purposes, methodologies, and outcomes of selected studies?

2. What were the subject matter domains, educational levels, and educational contexts of the selected studies?

3. What specific mobile devices were reportedly used in the learning process, and what was the geographical distribution of the selected studies?

\section{METHODOLOGY}

In this review, systematic aggregation and synthesis of existing literature was carried out to identify and analyze the most relevant articles from peer-reviewed journals. The study was conducted following the guidelines defined in the Preferred Reporting Items for Systematic Reviews and Meta-Analyses (PRISMA) statement (Moher, Liberati, Tetzlaff, Altman, \& The PRISMA Group, 2010).

\section{Literature Search Process}

A two-step literature search strategy was applied on several databases such as ProQuest, IEEE Xplore, Taylor and Francis, Science Direct and Scopus. At first, an initial limited search was conducted on all the selected databases followed by an analysis of the keywords used in the title, abstract and of index terms used to describe identified articles. The following keywords and index terms were used to identify studies and articles in this process: "mobile learning", "authentic learning", "authentic environments", "authentic contexts", "ubiquitous learning", "situated learning", "mobile augmented", "context-aware", "location-aware", and "contextual learning." Secondly, using all the identified keywords and index terms, a broad literature search was carried out on the selected databases for relevant articles. To identify the most recent trends in studies related to mobile device-based authentic learning, this review considered only the studies published in the past decade from 2010 to the time this article was being written (November 15, 2019).

\section{Study Selection and Eligibility Criteria}

The search of the databases has resulted in 174 potentially relevant articles. Of these, 27 articles were excluded due to duplication. After the removal of duplicated papers, 147 articles remained. Following that, the eligibility criteria were established to narrow down the target articles, which means that each article must be related to authentic learning facilitated using mobile devices in K-12 or tertiary learning environments such as colleges and universities. Furthermore, only research articles published in refereed journals were considered (i.e., conference papers and book chapters were excluded). Based on these, abstracts and full papers of the 147 articles were screened, resulting in the exclusion of 75 articles that failed to meet the set criteria. Finally, 72 
articles were retained for this review. Figure1 represents the literature search and review process.

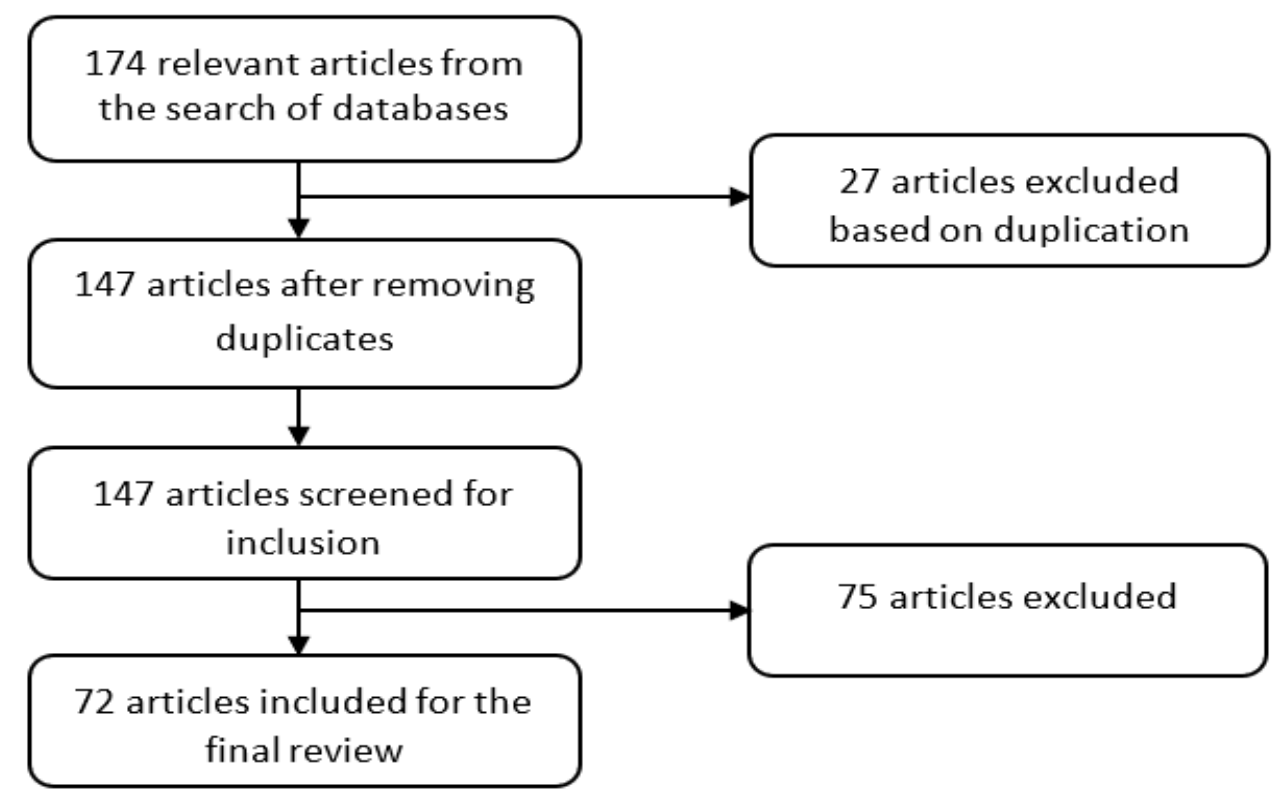

Figure 1: Literature Search and Review Process

\section{Coding Scheme and Process}

In order to systematically examine the studies related to mobile device-based authentic learning in educational contexts, a coding scheme was established based on the eight elements stated in the research questions. These include (1) research purposes (e.g., effectiveness, impact on learning, etc.); (2) research methods (e.g., quantitative, experimental, quasi-experimental, etc.); (3) outcomes (e.g., positive, negative, neutral); (4) subject matter domains (e.g., history, physics, biology, etc.); (5) educational levels (e.g., elementary, middle school, high school, etc.); (6) educational context (formal setting such as a lesson taking place in the classroom; informal or atypical setting such a lesson taking place in a playground); (8) types of mobile devices used (such as tablets, mobile phones, wearable technologies, and laptop computers); and (9) geographical distributions of studies (i.e., countries of studies). The articles were scrutinized thoroughly according to the coding scheme. Information falling under specific codes was extracted from each article and placed in its respective categories. The complete information in each code was then synthesized in a manner that addressed the research questions.

\section{RESULTS AND DISCUSSION}

Research Question One: What were the major research purposes, methodologies, and outcomes of the selected studies? 


\section{Research Purposes}

From the analysis of major research purposes of the selected studies, two codes were created: 1) Investigating the effects of mobile device-based authentic learning on student learning. Studies in this category assessed the effectiveness of mobile device-based tools, platforms, approaches and applications in facilitating student learning; and 2) Investigating the impact of authentic learning experiences on student learning. These studies evaluated the impact of mobile device-based authentic learning experiences of students on their learning, which included, for example, learning performances, motivation, participation, etc. The results of this coding are represented in Figure 2.

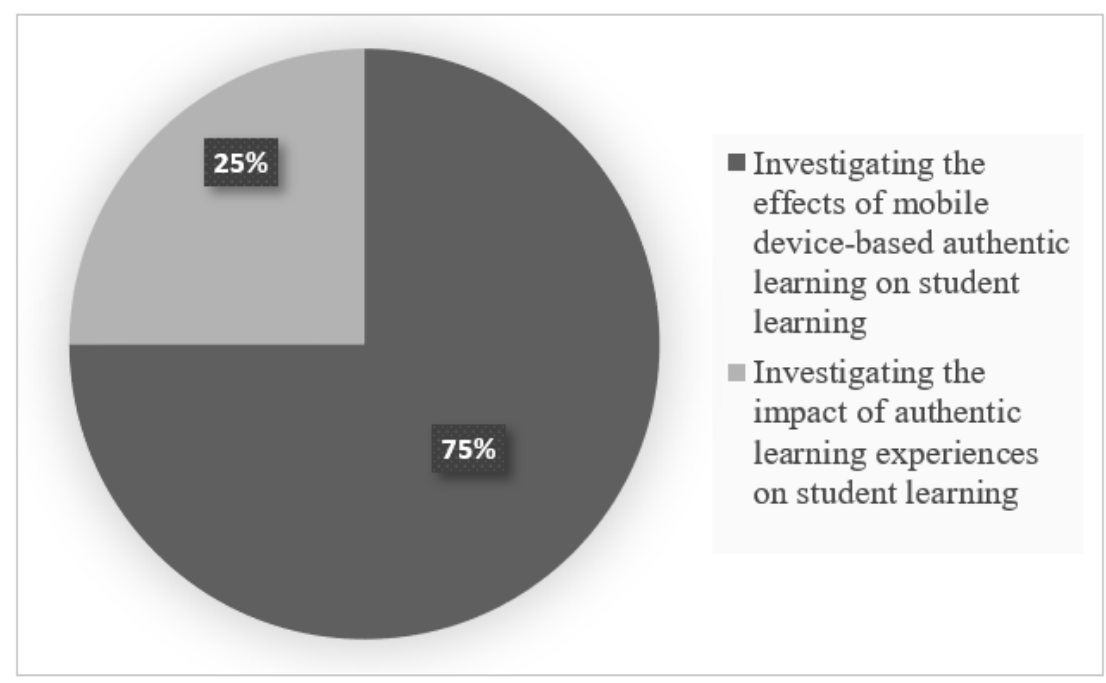

Figure 2: Research Purposes

The results showed that a large bulk of the studies (75\%) were conducted with the purpose or objective of investigating the effects of mobile device-based authentic learning on student learning. These studies had mainly proposed and evaluated the effectiveness of authentic learning systems, platforms, approaches, or applications specific to a certain subject area or a topic of learning. For example, Hwang, Utami, Purba, and Chen (2019) designed a mobile application called Ubiquitous-Fraction (U-Fraction) to help students to learn fractions in authentic contexts and assessed its effectiveness against students' learning behaviours and learning achievements. In another study, Kyza and Georgiou (2018) evaluated the effectiveness of mobile device mediated inquiry-based augmented reality (AR) authoring platform that helps to develop evidence-driven reflective inquiry-based mobile apps.

This finding regarding the effects of mobile device-based authentic learning is consistent with what has been found in previous systematic reviews carried out in the area (Crompton, Burke, a Gregory, 2017; Crompton, Burke, Gregory, \& Gräbe, 2016), where the primary focus of the studies were to design and evaluate the effectiveness of mobile device-based learning approaches and applications. Since the use of mobile devices as a medium to enhance authentic learning is relatively new, it is unsurprising to find that a majority of the studies have mainly focused on exploring the effects of a variety of different mobile device-based authentic learning systems and applications. 
The second most coded research purpose was investigating the impact of authentic learning experiences on student learning, with $25 \%$ of the studies in this category having had this objective. In these studies, the impact on student learning was usually explored from several angles. For example, studies have reported the impact of mobile device-based authentic learning experiences on student satisfaction, engagement, collaboration, awareness, problem solving and knowledge building (Daher, 2010; Harley, Poitras, Jarrell, Duffy, \& Lajoie, 2016; Hobbs \& Holley, 2016; Hsu \& Ching, 2012; Li \& Wang, 2018; Tirado-Morueta et al., 2019; Willemse, Jooste, \& Bozalek, 2018). In fact, this trend in research purpose is somewhat predictable as evaluating the impact of the use of authentic learning spaces on certain psychological constructs would be the very next step after the initial stage that involves designing the mobile devicebased authentic learning systems for learning.

\section{Research Methods}

As shown in Table 1, researchers have mostly used mixed-methods research $(n=35)$, followed by quantitative methods $(n=23)$, while the least used were qualitative methods $(n=14)$. Studies that adopted mixed-methods approaches have most commonly used the quasi-experimental research designs. In the same way, the quasi-experimental method was dominant in the quantitative category. However, for the qualitative category, case studies, content analysis, and observations were the most repeatedly used research methods.

Table 1:

Research Methods Used in the Selected Studies

\begin{tabular}{lll}
\hline \multicolumn{1}{c}{ Quantitative (23) } & \multicolumn{1}{c}{ Qualitative (14) } & \multicolumn{1}{c}{ Mixed (35) } \\
\hline Quasi-experimental (16) & Content analysis (4) & Quasi-experimental (12) \\
Case Study (2) & Experimental (3) & Case Study (4) \\
Survey (3) & Case Study (4) & Survey (3) \\
Experimental (2) & Interviews (3) & Content analysis (1) \\
& Observations (4) & Experimental (11) \\
& & Interview (1) \\
\hline
\end{tabular}

These results in Table 1 indicate that researchers have used a variety of research methods to examine the mobile device-based authentic learning from a variety of perspectives. An increased number of studies that used quasi-experimental and experimental methods have demonstrated the emphasis that researchers have given to carry out studies in experimental environments and real scenarios. These findings also support the recommendations of previous systematic reviews in the area of mobile learning. For example, Bano, Zowghi, Kearney, Schuck, and Aubusson (2018) stressed the importance of using a range of research methods, both qualitative and quantitative, to comprehensively explore and examine mobile learning experiences.

\section{Research Outcomes}

An overwhelmingly large number of studies (95\%) have reported positive outcomes, suggesting that a majority of studies on mobile device-based authentic learning support or enhance student learning. Only $1 \%$ of the studies have reported negative outcomes, while $4 \%$ of the studies have shown neutral outcomes. These results are represented in Figure 3. 


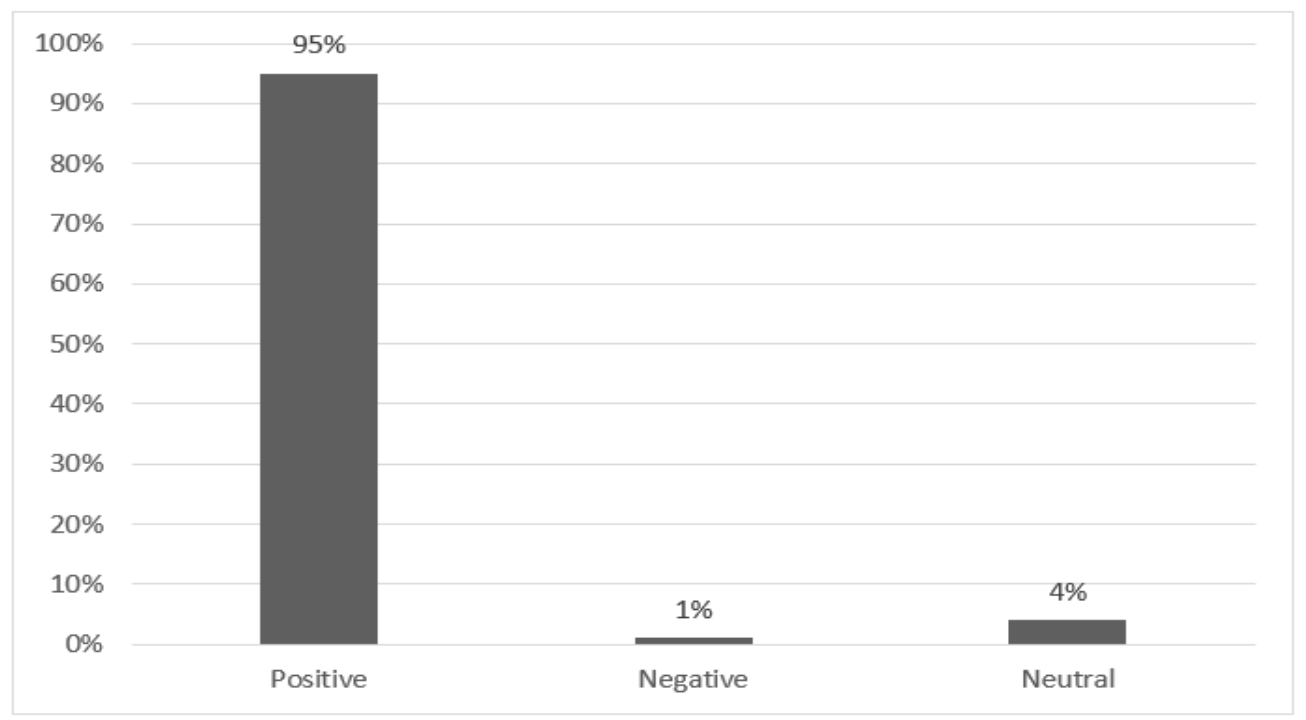

Figure 3: Research Outcomes of Mobile Learning Studies

These findings are also in agreement with the previous systematic reviews related to mobile learning (Crompton \& Burke, 2018; Crompton et al., 2017; Saleh \& Bhat, 2015). Possible factors that contribute to these positive outcomes may include the favorable effects of learning design on student motivation, curiosity and engagement, and even their familiarity with the device may contribute to positive outcomes. However, further studies should be undertaken to fully understand the causal relationships between mobile-based learning approaches and their respective outcomes.

Research Question Two: What were the subject matter domains, educational levels, and educational contexts of the selected studies?

\section{Subject Matter Domains}

As shown in Figure 4, the subjects were coded and categorized according to the disciplines that they best fit. Accordingly, four different categories of disciplines were created: Science, Literacy, Mathematics, and Humanities. Some studies have investigated the authentic learning experiences of students across two subjects that fall into two different disciplines. In that case, they are listed under 'Multiple Subjects' category. Other studies did not give any information regarding the subject matter domain; thus, they were coded as "Not Specified." 


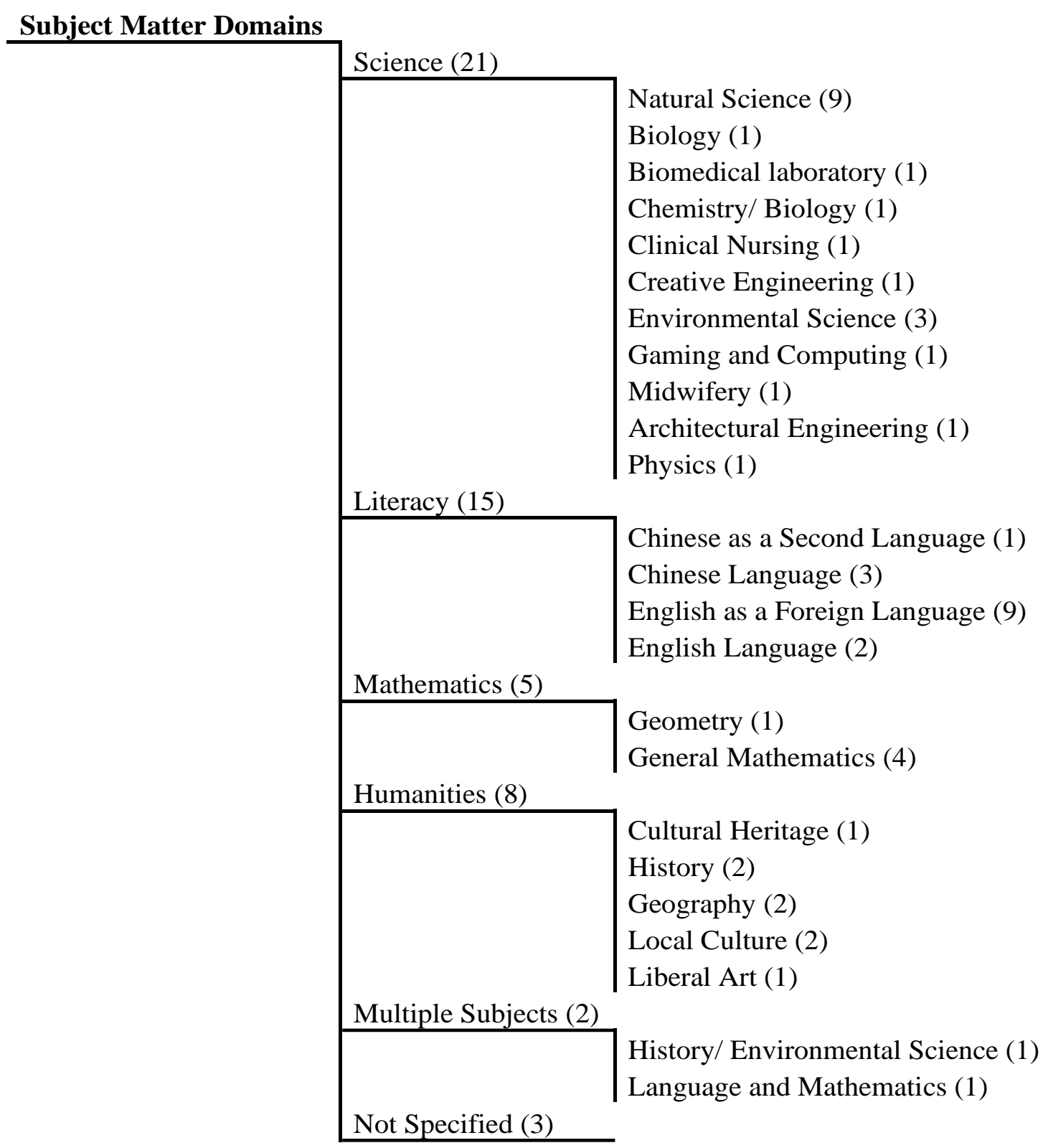

Figure 3: Breakdown of Subject Matter Domains

Consistent with the previous reviews related to mobile learning by Crompton et al., (2017), Liu et al. (2014), and Hwang and Tsai (2011), this research found that science was the most represented content area, with 21 studies in this category. Among the science subjects, natural sciences (i.e., subjects coded as natural science, biology, chemistry, and physics) were the most researched content areas $(n=12)$. By its very nature, science is an inquiry-based discipline, and mobile devices provide the tools to make the investigations easier and more accessible. Generally, studies that explored student learning of scientific concepts have adopted situated learning approaches where students inquire about real world phenomena in actual settings using mobile devices as scientific tools (e.g., Kissi \& Dreesmann, 2018; Zimmerman \& Land, 2014; Zimmerman, Land, Maggiore, \& Millet, 2019).

The second most studied subject discipline was literacy, with 15 studies in this category. English as a foreign language (EFL) was the most dominant subject in this category with 9 studies. Other subjects in this category included the studies on Chinese languages or dialects, 
Chinese as a second language, and English language. Research in this category has mostly studied the effects of mobile-assisted language learning in design-oriented authentic learning contexts. For example, Shadiev, Hwang, and Liu (2018) examined the outcomes of EFL learning activities supported by smart watches to combine learning with physical activities such as walking around the school community. In another study, Wong, Chin, Tan, Liu, and Gong (2010) studied the effects of photo sharing and online discussions using mobile phones among students in learning Chinese idioms.

Following literacy, the next most studied disciplines were humanities $(n=8)$ and mathematics $(n=5)$. Few studies belong to the coded categories of multiple subjects $(n=2)$, and not stated $(n=3)$. Among the subjects appearing in the humanities discipline included cultural heritage, history, geography, local culture, and liberal arts. Two subjects were listed under mathematics which included geometry and general mathematics.

\section{Educational Levels}

Over half of the studies were carried out at the level of elementary school (51\%), followed by higher education (22\%), high school (13\%), and middle school (8\%). No studies reported pre$\mathrm{k}$ or special education settings. These results are presented in Figure 4. In contrast to previous reviews which showed a majority of the studies in higher educational settings (Fu \& Hwang, 2018; Hedberg et al., 2018), the results of this study revealed that most of the studies were conducted at various grades of the elementary school level.

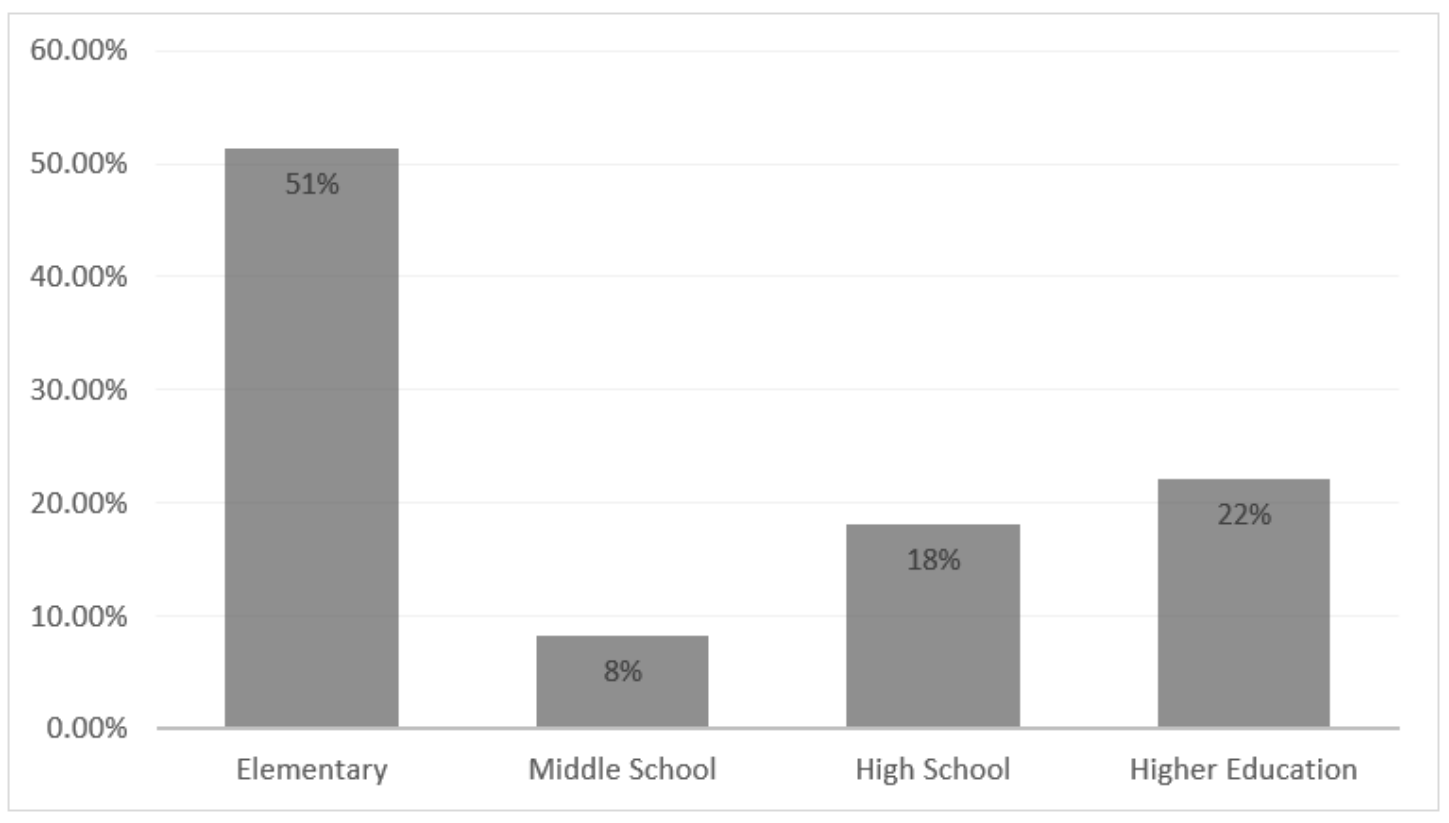

Figure 4: Educational Levels

\section{Educational Contexts}

In terms of educational contexts, the selected articles were classified as per the details given in the studies regarding the contexts in which the authentic learning activities took place. Accordingly, three codes were created: (1) formal (i.e., happening inside the classroom); (2) informal (i.e., happening outside the classroom, such as in nature); and (3) both formal and informal. As illustrated in Figure 5, most of the mobile device-based authentic learning. 
activities were conducted in informal settings $(n=52)$, followed with activities carried out in both formal and informal settings $(n=14)$, and the least coded were studies in formal settings, with only 6 in this category. These results reflect those of Chung, Hwang, and Lai (2018) who also found in their review of experimental mobile learning studies that a majority of the mobile device-based authentic learning studies had been conducted in informal contexts.

The types of mobile device-based authentic learning experiences in informal settings included, for example, home visiting activities ( $\mathrm{Pu}, \mathrm{Wu}$, Chiu, \& Huang, 2016), wayfinding in unfamiliar outdoor environments (Hergan \& Umek, 2017), observations in butterfly ecology gardens (Hwang, Chu, Shih, Huang, \& Tsai, 2010), and inquiry-based learning in botanic gardens (Kissi \& Dreesmann, 2018; Zimmerman \& Land, 2014). In comparison, authentic learning in formal contexts mostly included contextual learning in classroom settings facilitated through mobile devices. For example, Chen, Wang, Zou, Lin, and Xie (2019) studied the effects of theme-based EFL learning using the iMap navigation app in a simulation mode. On top of this, studies carried out in formal and informal settings mostly support seamless learning across contexts (e.g., Chang, Hsu, Wu, \& Tsai, 2018; Lin \& Lin, 2016).

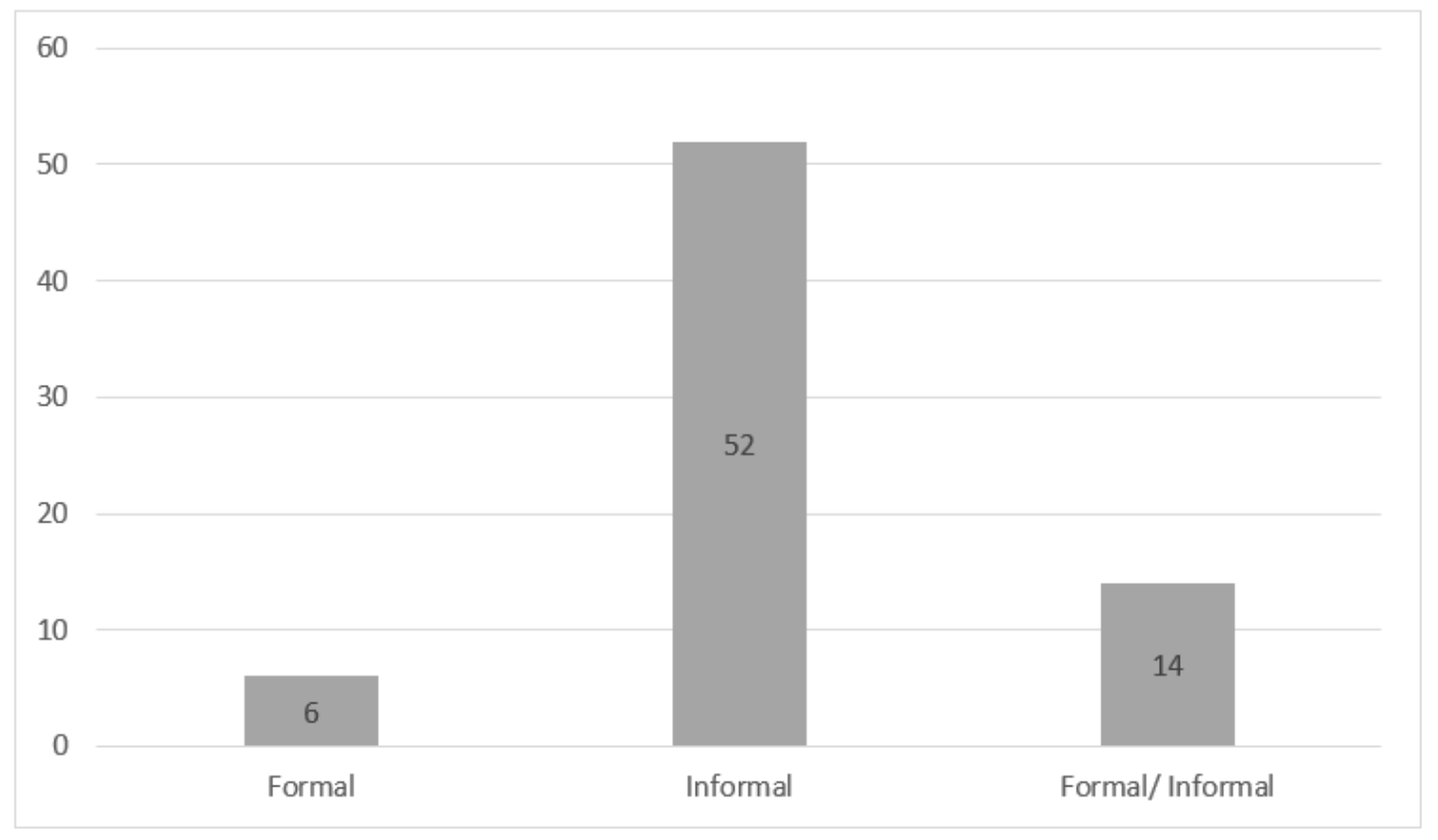

Figure. 5 Educational Contexts

\section{Research Question Three: What specific mobile devices were reportedly used in the learning process, and what was the geographical distribution of the selected studies?}

\section{Specific Types of Mobile Device}

As shown in Figure 6, a varied range of mobile devices were used in the selected studies to mediate learning in authentic contexts. Among these, the most commonly used device types were tablet computers $(n=31)$ and mobile phones $(n=20)$. Studies that adopted more than one type of mobile device were categorized as 'Multiple Devices', with 7 studies in this category. Few studies have used PDAs $(n=5)$, laptops $(n=2)$, wearable technologies like smartwatches $(n=2)$, and GPS navigation system $(n=1)$. Some researchers did not state the type of mobile device used in their studies; therefore, such studies were place in the category of "Other', with 4 studies in this group. 
The earlier reviews of mobile learning studies such as that of Ardzejewska and Imran (2015) found PDAs to be the most dominant device type. But later reviews have shown that mobile phones were the most predominant type (Crompton \& Burke, 2018; Crompton et al., 2017; Hedberg et al., 2018). In contrast to these previous studies, the findings of this study showed that tablet computers were the most commonly used device type in mobile device-based authentic learning. Possible explanations for the increasing use of tablet computers in authentic learning settings over other devices would be their affordability, ease of use and convenience, particularly in terms of their physical properties such as larger screen sizes and powerful and multiple functionalities.

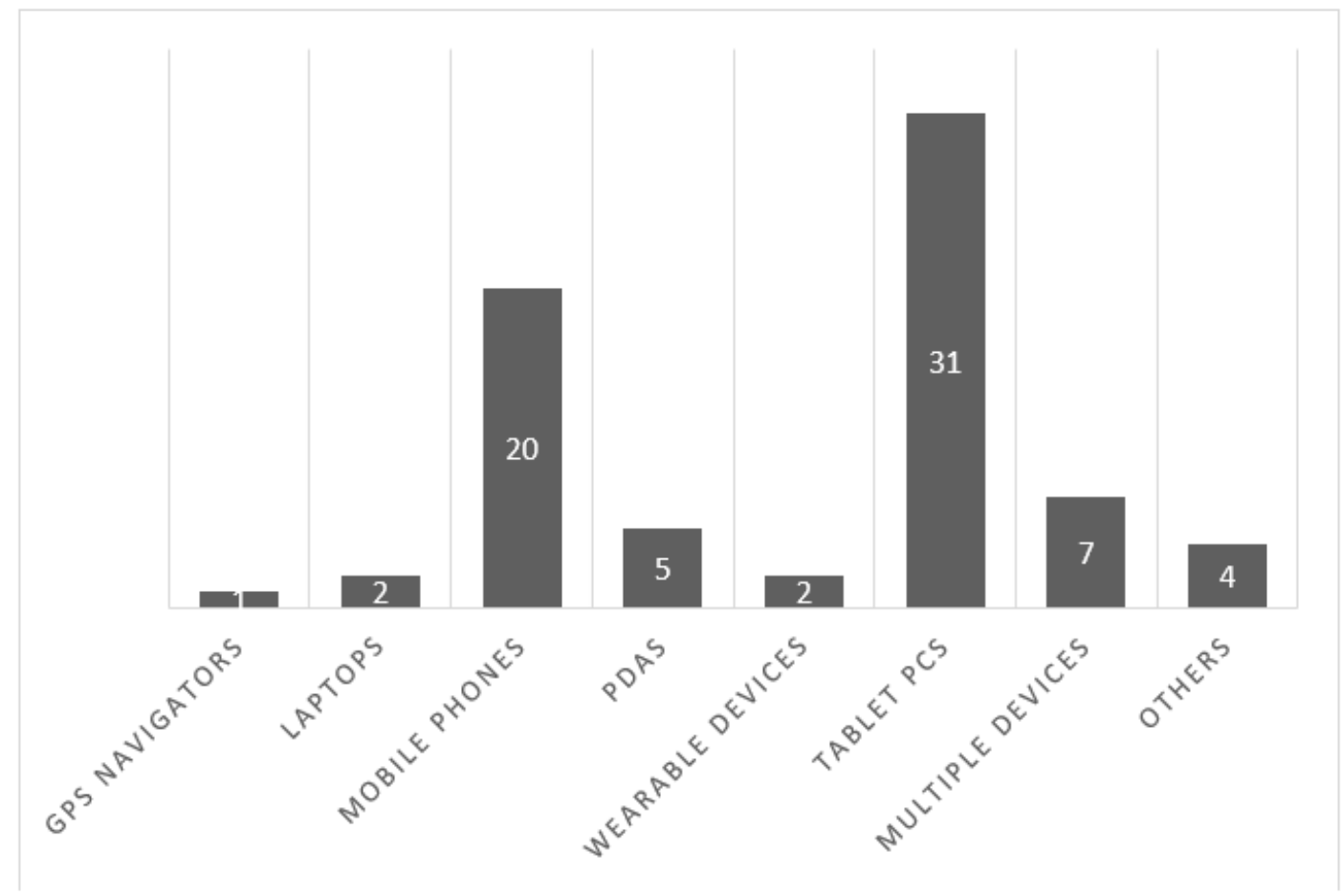

Figure 6: Types of Mobile Device Used in the Selected Studies

\section{Geographic Distributions of the Selected Studies}

As represented in Figure 7, studies on mobile device-based authentic learning were carried out in all continents except South America and Antarctica. Asia was the most active continent in this area of research $(n=45)$, followed by Europe $(n=15)$, North America $(n=8)$, Africa $(n=2)$, and Australia $(n=2)$. However, Malaysia is not included as one of the Asian countries that are actively researching mobile learning.

As for the individual countries, Taiwan contributed a substantial number of studies $(n=31)$, followed by Singapore $(n=8)$. These findings have revealed the fact that there is a disproportionate representation of countries in terms of research publications in this area, with a comparatively large number of studies from Taiwan and Singapore. These findings corroborate those of previous systematic reviews on mobile learning that a significantly greater number of studies have been carried out in Taiwan than any other country (Crompton et al., 2017, 2016; Hwang \& Tsai, 2011; Liu et al., 2014). The large numbers of research activities on mobile learning in specific countries could be due to the advanced technical infrastructure in place and policy emphasis on mobile learning in those countries. 


\section{Countries of Study}

\begin{tabular}{|c|c|c|}
\hline Asia (45) & & \\
\hline & $\begin{array}{l}\text { Taiwan (31) } \\
\text { Singapore (8) } \\
\text { China (1) }\end{array}$ & $\begin{array}{l}\text { Hong Kong (1) } \\
\text { Israel (1) } \\
\text { Thailand (1) }\end{array}$ \\
\hline Africa (2) & & \\
\hline & South Africa (2) & \\
\hline North America (8) & & \\
\hline & USA (8) & \\
\hline Europe (15) & & \\
\hline & $\begin{array}{l}\text { Cyprus (2) } \\
\text { Finland (3) } \\
\text { Germany (2) } \\
\text { Ireland (1) }\end{array}$ & $\begin{array}{l}\text { Scotland (2) } \\
\text { Slovenia (1) } \\
\text { Spain (1) } \\
\text { UK (1) }\end{array}$ \\
\hline
\end{tabular}

Australia (2)

Australia (1)

New Zealand (1)

Figure 7 Geographic Distribution of the Studies

\section{Identified Gaps and Future Research}

In this systematic review, five research gaps were identified. First, the published articles in peer-reviewed journals on mobile device-based authentic learning in the past decade amounted to only 72 studies. Indeed, more research is needed in this area to further understand the effectiveness of using mobile device-based authentic learning in multiple learning environments. Second, most of the studies were carried out in elementary schools. There is, therefore, a need for more research at other levels of education, specifically in higher education to ascertain the extent to which the use of mobile devices can advance university learning. Third, a majority of the researchers have concentrated on studying the subjects related to the science discipline, especially the natural sciences. More efforts are needed to investigate mobile device-based authentic learning in other subject areas such as education, the humanities, mathematics, and the arts. Fourth, studies in informal learning contexts are significantly predominant. Thus, more research is needed that focuses on experimenting student learning in formal and across contexts. Fifth, in terms of countries of study, it was found that there are disproportionate efforts to publish research articles in the area. Taiwan and Singapore have been predominant and active, while Malaysia and several other countries are acutely lacking in publication of their research in the field. Hence, more research is needed to inform the research community the experiences related to mobile device-based authentic learning in different country contexts. 


\section{LIMITATIONS}

The studies selected for this systematic review included articles collected from a limited number of databases (i.e., ProQuest, IEEE Xplore, Taylor and Francis, Science Direct and Scopus). Although exhaustive literature searches were carried out within the selected databases, some relevant articles may have been overlooked in the review process. Moreover, only peerreviewed journal articles published in the English language during a particular time frame were selected for analysis. In that, this review may not be a comprehensive representation of the research on mobile device-based authentic learning in the true sense of the word.

\section{CONCLUSION}

This systematic review has synthesized 72 high-quality research articles published in the past decade on mobile device-based authentic learning. The analyses of the studies have provided a snapshot of research on several domains such as major research purposes, methodologies, reported outcomes, educational contexts, subject area domains, types of mobile devices used, and the countries where the studies were conducted. From these analyses, research gaps were identified and the areas for future research are recommended.

When looking at the findings compiled in this review, it was found that mobile devicebased authentic learning is a growing research field. In addition, the findings have identified positive outcomes of using mobile device-based authentic learning in multiple settings and contexts, indicating that there is value in embracing the use of mobile technologies to facilitate student learning. Finally, and given the lack of studies and systematic syntheses of current knowledge in the area of authentic learning facilitated via mobile technologies, there is a need for more research, systematic reviews and meta-analyses to further empirically prove the potentials of mobile device-based authentic learning for schools, higher education and beyond. 


\section{REFERENCES}

Ardzejewska, K., \& Imran, A. (2015). Papers a Systematic Review of Mobile Learning Adoption in Higher Education : the African Perspective, 16(1), 1-18.

Bano, M., Zowghi, D., Kearney, M., Schuck, S., \& Aubusson, P. (2018). Mobile learning for science and mathematics school education: A systematic review of empirical evidence. Computers and Education, 121(February), 30-58. https://doi.org/10.1016/j. compedu.2018.02.006

Chang, H. Y., Hsu, Y. S., Wu, H. K., \& Tsai, C. C. (2018). Students' development of socioscientific reasoning in a mobile augmented reality learning environment. International Journal of Science Education, 40(12), 1410-1431. https://doi.org/10.1080/09500693. 2018.1480075

Chen, M. P., Wang, L. C., Zou, D., Lin, S. Y., \& Xie, H. (2019). Effects of caption and gender on junior high students' EFL learning from iMap-enhanced contextualized learning. Computers and Education, 140(December 2018), 103602. https://doi.org/10.1016/j. compedu.2019.103602

Chung, C.-J., Hwang, G.-J., \& Lai, C.-L. (2018). A review of experimental mobile learning research in 2010-2016 based on the activity theory framework. Computers \& Education, 129, 1-13. https://doi.org/10.1016/j.compedu.2018.10.010

Crompton, H., \& Burke, D. (2018). The Use of Mobile Learning in Hihger Education: A Systematic Review. Computers \& Education, 123, 53-64. https://doi.org/10.1016/j. compedu.2017.03.013

Crompton, H., Burke, D., \& Gregory, K. H. (2017). The use of mobile learning in PK-12 education: A systematic review. Computers and Education, 110, 51-63. https://doi.org /10.1016/j.compedu.2017.03.013

Crompton, H., Burke, D., Gregory, K. H., \& Gräbe, C. (2016). The Use of Mobile Learning in Science: A Systematic Review. Journal of Science Education and Technology, 25(2), 149-160. https://doi.org/10.1007/s10956-015-9597-x

Daher, W. (2010). Building mathematical knowledge in an authentic mobile phone environment. Australasian Journal of Educational Technology, 26(1), 85-104. https:// doi.org/10.14742/ajet.1104

Fu, Q. K., \& Hwang, G. J. (2018). Trends in mobile technology-supported collaborative learning: A systematic review of journal publications from 2007 to 2016. Computers and Education, 119, 129-143. https://doi.org/10.1016/j.compedu.2018.01.004

Harley, J. M., Poitras, E. G., Jarrell, A., Duffy, M. C., \& Lajoie, S. P. (2016). Comparing virtual and location-based augmented reality mobile learning: emotions and learning outcomes. Educational Technology Research and Development, 64(3), 359-388. https://doi.org/ 10.1007/s11423-015-9420-7

Hedberg, H., Nouri, J., Hansen, P., \& Rahmani, R. (2018). A Systematic Review of Learning Through Mobile Augmented Reality. International Journal of Interactive Mobile Technologies (IJIM), 12(3), 75. https://doi.org/10.3991/ijim.v12i3.8404 
Hergan, I., \& Umek, M. (2017). Comparison of children's wayfinding, using paper map and mobile navigation. International Research in Geographical and Environmental Education, 26(2), 91-106. https://doi.org/10.1080/10382046.2016.1183935

Herrington, J. (1997). Authentic learning in interactive multimedia environments. Edith Cowan University, Perth, Western Australia.

Herrington, Jan, Reeves, T. C., \& Oliver, R. (2014). Authentic Learning Environments. In J. M. Spector, M. D. Merrill, J. Elen, \& M. J. Bishop (Eds.), Handbook of Research on Educational Communications and Technology. New York, NY: Springer.

Hobbs, M., \& Holley, D. (2016). Using Augmented Reality to engage STEM students with an authentic curriculum. EAI Endorsed Transactions on E-Learning, 3(11), 1-8.

Hsu, Y. C., \& Ching, Y. H. (2012). Mobile microblogging: Using twitter and mobile devices in an online course to promote learning in authentic contexts. International Review of Research in Open and Distance Learning, 13(4), 211-227. https://doi.org/10.19173/ irrodl.v13i4.1222

Hwang, G.-J., \& Tsai, C.-C. (2011). Research trends in mobile and ubiquitous learning: a review of publications in selected journals from 2001 to 2010. British Journal of Educational Technology, 42(4), 65-70. https://doi.org/10.1111/j.1467-8535.2011. 01183.x

Hwang, G. J., Chu, H. C., Shih, J. L., Huang, S. H., \& Tsai, C. C. (2010). A decision-treeoriented guidance mechanism for conducting nature science observation activities in a context-aware ubiquitous learning environment. Educational Technology and Society, 13(2), 53-64.

Hwang, W.-Y., Utami, I. Q., Purba, S. W. D., \& Chen, H. S. . (2019). Effect of Ubiquitous Fraction App on Mathematics Learning Achievements and Learning Behaviors of Taiwanese Students in Authentic Contexts. IEEE Transactions on Learning Technologies, 1-11. https://doi.org/10.1109/tlt.2019.2930045

Kearney, M., Schuck, S., Burden, K., \& Aubusson, P. (2012). Viewing mobile learning from a pedagogical perspective. Research in Learning Technology, 20(1). https://doi.org/ 10.3402/rlt.v20i0/14406

Kissi, L., \& Dreesmann, D. (2018). Plant visibility through mobile learning? Implementation and evaluation of an interactive Flower Hunt in a botanic garden. Journal of Biological Education, 52(4), 344-363. https://doi.org/10.1080/00219266.2017.1385506

Kyza, E. A., \& Georgiou, Y. (2018). Scaffolding augmented reality inquiry learning: the design and investigation of the TraceReaders location-based, augmented reality platform. Interactive Learning Environments, 27(2), 211-225. https://doi.org/10.1080/ 10494820. 2018.1458039

Li, Y., \& Wang, L. (2018). Using iPad-based mobile learning to teach creative engineering within a problem-based learning pedagogy. Education and Information Technologies, 23(1), 555-568. https://doi.org/10.1007/s10639-017-9617-y

Lin, J. J., \& Lin, H. (2019). Mobile-assisted ESL/EFL vocabulary learning: a systematic review and meta-analysis. Computer Assisted Language Learning, 1-42. https://doi.org/10.1080 /09588221.2018.1541359 
Lin, Y. T., \& Lin, Y. C. (2016). Effects of mental process integrated nursing training using mobile device on students' cognitive load, learning attitudes, acceptance, and achievements. Computers in Human Behavior, 55, 1213-1221. https://doi.org/ 10.1016/j.chb.2015.03.076

Liu, M., Scordino, R., Geurtz, R., Navarrete, C., Ko, Y., \& Lim, M. (2014). A look at research on mobile learning in K-12 education from 2007 to the present. Journal of Research on Technology in Education, 46(4), 325-372. https://doi.org/10.1080/ 15391523. 2014.925681

Moher, D., Liberati, A., Tetzlaff, J., Altman, D. G., \& The PRISMA Group. (2010). Preferred reporting items for systematic reviews and meta-analyses: The PRISMA statement. International Journal of Surgery, 8, 336-341. https://doi.org/10.1016/j.ijsu.2010.02.007

Pu, Y. H., Wu, T. T., Chiu, P. S., \& Huang, Y. M. (2016). The design and implementation of authentic learning with mobile technology in vocational nursing practice course. British Journal of Educational Technology, 47(3), 494-509. https://doi.org/10.1111/bjet.12443

Saleh, S. Al, \& Bhat, S. A. (2015). Mobile Learning: A Systematic Review. International Journal of Computer Applications, 114(11), 975-8887.

Shadiev, R., Hwang, W. Y., \& Huang, Y. M. (2017). Review of research on mobile language learning in authentic environments. Computer Assisted Language Learning, 30(3-4), 284-303. https://doi.org/10.1080/09588221.2017.1308383

Shadiev, R., Hwang, W. Y., \& Liu, T. Y. (2018). A study of the use of wearable devices for healthy and enjoyable English as a Foreign language learning in authentic contexts. Educational Technology and Society, 21(4), 217-231.

Sung, Y., Chang, K., \& Liu, T. (2016). The effects of integrating mobile devices with teaching and learning on students ' learning performance : A meta-analysis and research synthesis. Computers \& Education, 94, 252-275.

Tirado-Morueta, R., Berlanga-Fernández, I., Vales-Villamarín, H., Guzmán Franco, M. D., Duarte-Hueros, A., \& Aguaded-Gómez, J. I. (2019). Study of a sequence to stimulate the engagement in one-to-one iPad programs at elementary schools. Education and Information Technologies. https://doi.org/10.1007/s10639-019-09974-4

Willemse, J. J., Jooste, K., \& Bozalek, V. (2018). Experiences of undergraduate nursing students on an authentic mobile learning enactment at a higher education institution in South Africa. Nurse Education Today, 74, 69-75. https://doi.org/10.1016/j.nedt. 2018.11.021

Wong, L. H., Chin, C. K., Tan, C. L., Liu, M., \& Gong, C. (2010). Students' Personal and Social Meaning Making in a Chinese Idiom Mobile Learning Environment. Educational Technology \& Society, 4(13), 15-26.

Zimmerman, H. T., \& Land, S. M. (2014). Facilitating Place-Based Learning in Outdoor Informal Environments with Mobile Computers. TechTrends, 58(1), 77-83. https://doi.org/10.1007/s11528-013-0724-3

Zimmerman, H. T., Land, S. M., Maggiore, C., \& Millet, C. (2019). Supporting children's outdoor science learning with mobile computers: integrating learning on-the-move strategies with context-sensitive computing. Learning, Media and Technology, O(4), 116. https://doi.org/10.1080/17439884.2019.1667823 